\title{
Cuando la historia la hacen las mujeres: El caso de las comunidades de repatriados
}

\author{
Alvaro Artiga-González
}

\section{Introducción.}

Cuando Segundo Montes se puso a investigar los fenómenos de desplazados, refugiados y repalriados salvadorefios quedó sorprendido de lo que sus ojos velan. Para él, se trataba de "una experiencia muy rica en contenidos sociales y económicos innovadores...un fenómeno posiblemente único y digno de estudio, análisis y aprendizaje de pautas y valores...un hecho social novedoso $\theta$ innovador, que obsesiona a cualquier cienlíitico social" (Montes, 1989:pp.28;43-44;51). Con todo, no llegó a preguntarse si los logros alcanzados lenian que ver con la presencia y participación masiva de las mujeres de esas comunidades. Tampoco le dieron tiempo (caía asesinado en noviembre del 89) para esludiar los cambios operados en las relaciones entre hombres y mujeres a partir de la experiencia del exilio y que fueron modificando la vida cotidiana en esos grupos. Para no dejar truncado entonces el estudio de esta experiencia irrepetible (y de la cual muchos logros pueden perderse con el paso del tiempo), el Departamento de Sociología y Ciencias Políticas de la Universidad Centroamericana "José Simeón Cafias" desarrolló (como un trabajo de graduación) la investigación: "ALTERNATIVAS DE DESARROLLO DE LA MUJER EN LAS COMUNIDADES DE REPATRIADOS, AnOS 1988-1991", la cual fue presentada en Febrero de 1992. El fin de la 
guerra y la transición hacia la paz eslable y duradera exigen no olvidar todo lo que pasó en la década de los 80 . La verdad de estas experiencias también debe salir a la luz y no quedarse guardada en ninguna biblioteca. Con esla intención, se ha querido publicar un extracto de esa investigación en lo relacionado a la historia de las actuales comunidades de repatriados.

\section{De campesinas a refugladas.}

\subsection{El nuevo carácter de las migraclones de los $\mathbf{8 0}$.}

Los movimientos migralorios de los 80 en El Salvador, luvieron un marcado carácler político que los diferenció, cuantilativa y cualitativamente, de los movimientos migratorios tradicionales originados más por molivos económicos (Montes,1985). Plásticamente hablando, el país entero presenció las "oleadas" de población que huía de sus lugares de origen buscando salvaguardar lo único que podian llevar consigo: sus vidas. Las zonas más afectadas lueron aquellas más pobres y retrasadas del pals: Chalalenango, Cabañas, Cuscallán, Morazán, Usulután y San Vicente. Algunos de estos departamentos ya eran tradicionalmente "expulsores" de población.

Básicamente podríamos distinguir cuatro lipos de "éxodos masivos": hacia los lugares de refugio en San Salvador y cabeceras departamentales; hacia las zonas marginales de San Salvador y cabeceras departamentales más seguras; las comunidades "errantes" o en "guindas" que se movilizaban en el interior del país según el desarrollo de los combates militares; y el éxodo hacia otros países (Honduras, Nicaragua, Costa Rica, Estados Unidos, Canadá, Suecia y Ausılralia).

¿Qué tipo de genle era la "normalmente" afectada? En el caso del éxodo hacia otros países de la región centroamericana "normalmente se trataba de población eminentemenle rural. Antes de huir, cultivaban y poseian o alquilaban tierras en forma individual-familiar, dispersos en el campo y cada lamilia procedía en lo lundamental en forma privada, separada e individualista (Concertación,1991:p.86; Montes,1989:p.26). Los que huyeron hacia paises fuera de la región, no sólo tenian otra extracción social sino que el mismo éxodo fue dislinto, hasta con mayor cobertura institucional, excepto para el caso de los que migraron hacia Estados Unidos de América.

La población que se vió forzada al desplazamienlo, a abandonar sus lugares de origen, eslaba compuesla mayoritariamenle por mujeres, nifias. nifios ancianos y ancianas. La ausencia de hombres en edad productiva y reproductiva por ejemplo, podía explicarse por su presencia en los frentes 
de guerra en cualquiera de los bandos en conflicto, o porque ya habian sido blanco de la represión o de la violencia insurgente.

Antes de la huída, el indice de analfabetismo de esta población era elevado, muy cerca del $85 \%$; para la siembra utilizaban técnicas muy primitivas y eran marginados de los avances de la civilización modema y sus beneficios, a parte de estar separados de los procesos y sociedad en general, con un fatalismo mítico y Iradicional, con una cosmovisión atávica, aclilud supersliciosa y afincada en el pasado (Montes,1989:p.44).

Es importante a estas alturas hacer una distinción: aún cuando la procedencia de los desplazados y refugiados haya sido semejante, los procesos y experiencias en el lugar donde buscaron "seguridad" forjaron dilerencias al ser procesos y experiencias diferentes. Es actualmente cuando se manifiesla claramente esla diferencia en lo que se ha denominado repoblación y repalriación.

Calegorias a tener presente en el estudio de las migraciones políticas de los 80 .

Desplazados: Las personas que, debido a fundados temores de ser perseguidos por motivos de raza, religión, nacionalidad, pertenencia a un gnupo social determinado u opinión polilica, se encontraban fuera de su lugar de residencia, pero dentro de su propio país, y no podían o, a causa de esos temores, no querian regresar a su lugar de residencia (Monles, 1989:p.6).

Relugiados: Las personas que, debido a fundados temores de ser perseguidos por motivos de raza, religión, nacionalidad o a pertenencia a un grupo social determinado u opinión politica, se enconlraban luera del pais y no podlan 0 , a causa de esos temores, no querian acogerse a la protección del mismo (ibid).

Repobladores: Los desplazados que retornaron a su lugar de origen -0 a sus proximidades - ya sea en forma individual, familiar o comunitaria y colectiva (ibid).

Repatriados: Los refugiados que relornaron al pais, ya sea en lorma individual, familiar o comunitaria y colectiva, y que objeliva y subjetivamente se decidieron (al menos en los primeros años), por un proyecto de vida colectiva.

Finalmente, hay que agregar que en los casos considerados en la 
invesligación, no fue raro encontrarse con población simpatizante del frente guerrillero o población civil sospechosa, para el gobierno en turno y las fuerzas armadas locales, de ser colaboradora, base social de la guerrilla. Lo que hay que afirmar es que en esta población se fueron geslando unas condiciones subjetivas lavorables a la posterior experiencia organizativa en los refugios. Hay que sefnalar también el trabajo pastoral-social que ya realizaba un buen sector de la Iglesia salvadorefia en muchos lugares del campo; desde la creación e impulso de las comunidades eclesiales de base hasla el fomento, ya tradicional, de cooperativas y experiencias comunitarias. Es interesante la observación que hacia $S$. Montes al respecto: "posiblemente el caso más conocido sea el de la zona de Aguilares, al norte del departamenlo de San Salvador, (...). Sin embargo, por amplias y vaslas zonas del campo, se exlendieron experiencias similares y se arraigaron nuevas comunidades cristianas (...) la nueva pastoral se lue introduciendo en el Norte de San Salvador y de Cuscatlán, en el departamento de Chalatenango, en Cabañas y zonas de San Vicente y La Paz, en la zona rural de Usulután, en el Norle de Morazán, con proyección hacia áreas colindantes de los departamentos de San Miguel y La Unión. Si se examina el actual mapa de persistencia y mayor influjo de las fuerzas insurgenles, aparece una correlación estrecha con los lugares de mayor trabajo pastoral de liberación" (Montes, 1988:p.86).

\subsection{Lo masivo del tenómeno.}

Enfatizamos que olra nola nueva de los movimienlos migralorios de los años ochenla, era que se trataba de desplazamienlos masivos, a veces de poblaciones enteras, la mayoría de las veces en medio de bombardeos y operativos militares, to que les imposibilitaba llevar las respeclivas pertenencias. Desplazamientos que fueron vividos entre la vida y la muerle y que dejarian una profunda huella en la subjetividad de los afectados.

Según dalos del Allo Comisionado de las Naciones Unidas para los Refugiados (ACNUR), cilado por S. Monles (1985:p.35), para Mayo de 1984 exislian en Centroamérica y México, alrededor de 245,500 refugiados salvadorefios entre dispersos y concentrados, distribuidos asi:

$\begin{array}{lr}\text { Belize } & 7,000 \\ \text { Costa Rica } & 10,000 \\ \text { Guatemala } & 70,000 \\ \text { Honduras } & 20,000 \\ \text { México } & 120,000 \\ \text { Nicaragua } & 17,500 \\ \text { Panamá } & 1,000 \\ \text { TOTAL } & \mathbf{2 4 5 , 5 0 0}\end{array}$


De este gran total, cerca de 30,000 refugiados constituian las experiencias de repatriación consideradas en la investigación.

Ahora bien, lo masivo del fenómeno no debe leerse sólo en las cantidades de refugiados, debe agregarse la cantidad de pérdidas materiales, entre vivienda, tierras, animales y otros, para la población afectada. Según S. Montes (1989:p.238), los acervos perdidos para la población salvadorena afeclada por el fenómeno en cuestión, alcanzaron los $\$ 67,940,462$. Pero existia otra masividad que tiende a ser pasada por allo cuando se quiere magnificar el problema. La vida cotidiana, esa realidad que se nos impone por excelencia, ese mundo de relaciones sociales en el que nos vemos incorporados al formar parte de la sociedad, se desmoronó en cuestión de horas. Lo colidiano dejó de serlo y lo nuevo irrumpió masivamente en la historia personal y colectiva de eslos grupos humanos. Masiva y violentamente se desmoronaba una particular forma de enIrentar la vida. Masivamente lambién comenzaba una nueva vida.

En la investigación realizada se anola que ante los operativos de contrainsurgencia que incluían caleos, quema de casas y cosechas y asesinatos indiscriminados, miles de personas del Departamento de Morazán se vieron lorzadas a huir hacia Honduras. Del 7 al 29 de Diciembre de 1981, se dice que más de 1000 personas entre hombres, mujeres y niños, fueron asesinados en los cantones El Mozole. Cerro Pando y Poza Honda. Los flujos de personas hacia Honduras fueron creciendo y si ya vivían en situación de extrema pobreza, su nueva condición fue peor. La huída la hacían en grupos que incluian familias y personas solas. Procedian de los cantones La Guacamaya, El Progreso, Ojos de Agua, Raíces, Santa Anila y El Zapole; se instalaron a escasos $10 \mathrm{kms}$. de la frontera con El Salvador, en territorio hondurefio, en el municipio de Intipucá. Desde 1980 hasla febrero de 1986, a pesar de los cercos y presiones militares, el flujo de personas hacia el relugio de Colomoncagua se mantuvo. El deseo de salvar "aunque sea la vida" podía más que cualquier obstáculo.

Por otro lado, gente procedente de los cantones de Portillo, Ocotillo y Honduritas en Nueva Esparla, La Unión, decidieron abandonar sus hogares trente a los bombardeos de la Fuerza Armada. No habia dónde defenderse, les quemaron sus casas, andaban huyendo, se refugiaban en los monles, en cuevas Aún cuando vivian retirados en sus lugares de origen, luego de "aquel bombardeo de todo el dia, en la noche se agrupó la gente, porque ya no podiamos regresar a los lugares donde viviamos, porque las casas ya no existian... y las que existian daba mucho miedo para regresar, porque sabiamos que si regresabamos moriamos" (Repatriada de Ciudad Romero). Durante la huída, cada madre iba cargando a 
sus hijos, no f́evaban más pertenencia que lo que llevaban consigo, puesto. Los hombres que les acompanaban, ayudaban a cargar también. El éxodo lo hicieron a tientas, adivinando. Eran cerca de 500 personas. Por varios meses estuvieron en terrilorio hondureno, pasaron muchos sufrimientos, durmieron en el zacale y su alimento eran los mangos, pues no tenlan otra cosa que comer. Por lo duro de la situación, cerca de 150 personas regresaron al pais a los lugares que hablan abandonado. Algunos de ellos todavia vivían alli en el momento del retomo. Para el resio, a la intemperie, bajo los árboles, bajo el sol y la lluvia, su siluación era de lo más angustiosa hasla que el ACNUR les visitara y les reconociera como "refugiados". Este les propuso México o Panamá como refugio. Ellos decidieron viajar a Panamá, "por sentirlo más cercano a nuestra patria" (Ciudad Romero,1991:p.2).

Finalmente, procedentes de Chalatenango, La Libertad y San Vicente, un gran número de familias llegan al relugio de la Iglesia de San Roque en San Jacinto. San Salvador. Los que ahora forman la comunidad de Nueva Esperanza, en el sur de Usulután, procedian básicamente de Chalalenango. Durante dos afios permanecieron en el sólano de la lglesia; la mayoria eran mujeres y nifios, lambién ancianos. "Ese tiempo fue un tiempo serio, de anguslia, lue el afio de la masacre en el Sumpul, ese ano rebalsó todo mundo, fue que decidimos nosotros también salir de alli... todos salimos en un solo grupo y desde allí comenzó a nacer la comunidad" (Repatriada de Nueva Esperanza).

\subsection{Significado: ruptura violenta con el orden social.}

"Nosotros salimos en grupos. Nos reunimos todos y salimos en grupos. La situación en esos dias eslaba bien dura y nos salimos por salvar a nuesiros hijos. Tuvimos que salir para Honduras; pues sí, andaban bombardeando y no habia otra salida" (Repatriada de Ciudad Romero).

"Eslas masacres junto a las decenas que no se han mencionado, iban acompañadas de la desirucción de viviendas, cosechas cultivadas y atmacenadas, malanza de animales de corral y de trabajo, etc. Todo era destruido, la idea era forzar a la población a que abandonara estos lugares"(Concerlación, 1991:p.9).

Como la "salida" fue forzada, hablamos de "ruptura violenta" y como fue una "salida del país", enlonces hablamos de "ruplura violenia con el orden social". Las mujeres que durante su vida toda habian sido campesinas, las nif́as y adolescenles que estaban "destinadas" a ser campesinas, lodas aquellas para quienes el campo (con lodo el mundo de relaciones sociales que implica) era su mundo, se vieron forzadas por una institución patriarcal-clasista por excelencia, a salir huyendo para poder 
salvar sus vidas. Desde ese momento, la vida en el exilio iba a producir modificaciones importantes en sus vidas, a tal grado de cuestionarse ahora su identificación con una tradicional y "estereotipada" campesina. o por lo menos se convierten en un "dato" más acerca de lo heterogeneo del campo. Sin pretenderlo, aquella inslitución típicamenle patriarcal, donde la jerarqula, el autoritarismo y la prepotencia son notas propias, al producir el fenómeno de los refugiados estaba creando condiciones óptimas para el surgimiento de un nuevo orden social en eslos grupos. Malentalmente hablando, sobre las cenizas del viejo mundo naceria un nuevo mundo de relaciones sociales, nuevas actitudes frente a la vida y la naturaleza. Paradójicamente, la posibilidad de ser algo más que amas de casa comenzaria a hacerse realidad. No precisamente como produclo de una lucha ferninista, sino por la "necesidad". En el plano familiar, muchas mujeres pasarian a asumir los roles de padre y madre, luego que sus companeros-maridos murieron o desaparecieron. La pérdida de companeros e hijos, la fruslración de no poder alimenlar mínimamente a sus hijos $\theta$ hijas y la adaptación a un nuevo ambiente, produciría en muchas de ellas, severos trastornos, depresión, dolores de cabeza, insomnio, anguslia; es decir, algo que podríamos llamar "un eslado de muerte en vida".

\section{La transición: Construyendo un orden soclal nuevo.}

No todos los relugiados salvadorenos en los demás países de la región cenlroamericana estaban concenirados en campamentos. Los casos de Honduras (Mesa Grande, San Antonio y Colomoncagua), de Nicaragua y Panamá (Ciudad Romero) se cuentan entre los que dieron origen a la mayoria de comunidades de repatriados. Las experiencias en el exilio, no obstante la similitud de la huida, fueron diversas. Desde el aislamiento lotal, aunque sin hostilidades del Gobierno y fuerzas armadas locales como en el caso de Panamá, hasla la integración con población local y ayuda gubernamental, como lo tue el caso nicaragüense. Las tres experiencias de Honduras tuvieron olra serie de elementos que deben considerarse: especialmente la hoslilidad, lanlo del Gobierno de lurno como de las fuerzas armadas hondurenas, las amenazas, los cercos militares, la sospecha y presión psicológica sobre la población, el sabolaje a sus programas de desarrollo; además de la cercania al pais que posibilitaba un conlínuo flujo de refugiados como de repatriaciones individuales; lodos eslos hechos lavorecerian una mayor solidaridad, cohesión y organización en los campamentos (entre más tiempo mayor seria el eleclo) que haría posible los logros alcanzados por la población repalriada, entre ellos, muy especialmente, el haber retornado a sus 
lugares de origen y en la forma como ellos lo plantearon a pesar de la oposición gubernamental que siempre trató de posponer y cambiar la forma del retorno (ECA, 1987:pp.713-718).

\subsection{El entorno que los vió y los hizo nacer: los refuglos.}

Por distinlos periodos que oscilan entre 5 y 11 años, los grupos de salvadorenos y salvadorefias en el exilio, vivieron un tiempo de "experiencia-aprendizaje". Las lormas y los contenidos de ésta eslán ligadas con el espacio lísico en donde luvo lugar. Por supuesto, que existieron olros condicionantes que pueden explicar diferencias entre las actuales repatriaciones, pero de alguna manera, también estaban ligadas con la ubicación de ese espacio físico. Por ejemplo, la cercania de Colomoncagua a El Salvador, permitió que los grupos allí refugiados fuesen más numerosos, varios miles. Este hecho condujo a una organización del campamento en sub-campamentos y colonias. Esta subdivisión y lo numeroso, provocaría la necesidad de los representantes, los comités. Esta institucionalización, producto de una externalización nueva para muchos en el refugio, se fue constituyendo en lo esencial: la comunidad. La cercania al país les haría estar más expuestos a hostigamientos de parte del ejército hondurefio, pero ésto a su vez, favorecería el grado de cohesión interna de los grupos. Desde mayo de 1985 hasta septiembre de 1989, el ejércilo hondureño mantuvo un cerco mililar_en el campamento de Colomoncagua. Así, el refugio se convirtió en "una cárcel sin paredes", en un "sepulcro vivo". En la producción, el hecho que estuvieran ubicados en un lugar donde existía el barro, lavoreció el desarrollo de la altarería, șea que la praclicaran ya anles del exilio o no.

Los relugiados en Nicaragua, tuvieron quizás las condiciones más tavorables aunque tal vez no las mejores a juzgar por los logros comparados. Al eslar incorporados a una cooperaliva de nicaragüenses y salvadorefios, su experiencia-aprendizaje estuvo más vinculada con 10 agropecuario. Por otra parte, la Nicaragua Sandinisla les proveyó, por un periodo de 9 años, un ambiente más tranquilo y estable. Ello favoreció la apertura de la comunidad: en relaciones comerciales, en su acceso a bienes y servicios producidos en ese país, en sus relaciones sociales con los vecinos, al intercambio cultural inclusive.

El caso más duro (de los que se exponen en este trabajo) lo conslituyeron los refugiados en Ciudad Romero, Panamá. Los más alejados del pais y casi por once años Un grupo formado por 365 personas que casi se duplica en el extranjero. Metidos en un rincón de la costa atlántica panamena, a diez horas de viaje por mar, en cayuco con motor fuera de borda, de la ciudad de Colón, enlrentaron problemas inimaginados. No 
enfrentaron un hosligamiento de Gobierno ni ejército alguno, pero sí las inclemencias del tiempo y de to inhóspito del lugar. Asl aprendieron a hacer cayucos para transportarse por los rlos y rompiendo el miedo al agua del rlo y del mar, tuvieron que aprender a nadar. Por supueslo que a las mujeres la vida se les complicaba más y velan asi más limitadas sus posibilidades de movilización debido a esta serie de condiciones geográficas (la limitación a su movilidad ahora venia de la naturaleza y no solo de parte de los hombres). Anadamos también que siendo un medio selvático, habian muchas serpienles; eslas condiciones eran pues, equivalentes naturales al peligro que para sus vidas eran las luerzas armadas de su pais de origen.

\subsection{La necesidad de Organlzarse.}

En general, aunque con sus matices según el lugar de refugio, la sobrevivencia, organización y posterior desarrollo de la comunidad, fue posible en parte, por la ayuda que recibían de iglesias cristianas locales. grupos de solidaridad internacional, agencias y organismos de asistencia, fueran éslos nacionales o internacionales. Pero, por otra parte, el esfuerzo y ahínco de los relugiados salvadorenos fue un hecho insoslayable y que permite explicar diferencias con respecto a la experiencia de otros refugiados centroamericanos cuando se habla de sus logros (Montes, 1989:pp.31-46).

Una población conslituida mayoritariamenle por mujeres, nif́os, y ancianos, sin pertenencias personales, sin experiencia organizativa y comunitaria. Anallabelos en su mayor parte, fueron capaces de organizarse según la siluación del refugio lo exigia y atendieron áreas de trabajo como: producción agropecuaria y artesanal, salud comunitaria, educación y cullura, infraestructura, relaciones y comunicaciones, alimentación, comercialización, distribución y tareas administrativas. Es claro que no fue algo hecho de la noche a la mañana. Es producto de una continua aclividad translormadora lanto de hombres como de mujeres frente al mundo que les rodeaba y frente a ellos mismos. Poco a poco se les apareció como ajena a sus voluntades, especiaimente para los pequefios que iban naciendo y creciendo en los relugios. Ciertamente se eslaba construyendo un orden social nuevo con relaciones sociales nuevas entre grupos y entre géneros. Algo diferenle a las tradicionales relaciones palriarcales, por lo menos a nivel de objelivación, se eslaba gestando.

En relación al nuevo mundo que ellos mismos construian, cuentan los ex-refugiados en Colomoncagua (ahora Ciudad Segundo Montes) que, al llegar a Honduras, uno de los problemas (nuevos en aquel momenlo) con los que se encontraban era el de buscar una forma de coordinación 
adecuada, tanto a las necesidades como para administrar los pocos recursos que les brindaba la solidaridad y agencias humanitarias. En las asambleas abiertas (práctica que se hizo muy frecuente y que revela la vida democráctica de la comunidad) se eligieron a los primeros coordinadores para dirigir el reparto de los alimenlos. Ya en el campamento. surgieron otras necesídades y, por tanto, nuevas formas de organización. El eje político de la organización era la aplicación de métodos democráticos que permitlan recoger las opiniones de todos y orientar la acción en función de los intereses de toda la comunidad. Esta siluación era nueva para las mujeres campesinas que ahora habian exlendido su mundo privado hacia la comunidad. Su participación comenzó a ser decidida, relevante; por supuesto, eran los intereses tradicionales los que estaban en juego, especialmente la vida.

Por su parte, los refugiados en Nicaragua comenzaron su convivencia incluso antes de salir hacia San Roque en San Salvador: "al haber ese gran problema del ejército, que habian cateos, que leniamos que salir por las tardes (a dormir a los montes) y con ese proyeclo de tierra arrasada que venía, la comunidad práclicamente se unió, se formó un grupo que vino a hablar con el Arzobispado y con la Cruz Roja, para que fueran a sacar a la gente" (Repatriada de Nueva Esperanza). Al ser trasladados a León, Nicaragua, la genle comenzó a sentir el deseo de lormar una cooperativa y trabajar. Hicieron gestiones con el ACNUR para que les apoyara y poder conseguir tierras por otros lados. Lograron un terreno cerca de Managua y alli se integraron a una cooperativa. "EI trabajo en cooperativa era una experiencia nueva para nosotros" (Comunidad Nueva Esperanza,p.2). Poco a poco se fueron adaptando y enfrentando una situación general adversa por la guerra contrarrevolucionaria y el bloqueo norteamericano. Algunos proyectos se les venían abajo. Pero su vivencia comunitaria y su le en Dios les permilian salir adelante. Aprendieron a hacer escobas e iniciaron proyectos de artesanias, sastreria y panaderia. Su organización eslaba pues en función de sus necesidades.

Finalmente, los refugiados en Panamá lambién luvieron cierta experiencia comunilaria previa a su instalación definitiva en Ciudad Romero. Su esladla en Honduras por varios meses les lue consolidando como comunidad. En la base militar de Cimarrón, permanercieron en recuperación cinco meses: "sólo comlamos y dormíamos" (Repatriada de Ciudad Romero). Fueron trasladados a la costa Allántica y su primer larea fue "derribar palos para construir nuestras casas y empezar a sembrar lo necesario para comer. Poco a poco fuimos haciendo con nuestras manos lo que posteriormente baulizamos como Ciudad Romero" (Ciudad Romero, 1991 :p:2). Hombres y mujeres tuvieron que apoyarse, los primeros "botando montana" y las segundas "cocinando para todos". Constru- 
yeron una capilla y una escuelita. Trabajando en grupitos montaron proyectos de cacao, café, coco, ganadería.

El acompanamiento de la Iglesia panamefía siempre estuvo presente. Su orgànización pastoral lacilitaria su posterior organización de la vida comunitaria. "El equipo misionero de Colón, a cargo de Monsefior Carlos Marla Ariz, estuvo siempre dando ánimo para caminar en nuestra fe y en nuestra vida de refugiados. Ellos siempre fueron una presencia de esperanza y una sefnal que al menos por Dios, no habiamos sido abandonados" (Ciudad Romero, 1991: p.3).

\subsection{La necesidad empuja a las mujeres a dejar su vleja externali- zaclón.}

Anles del exilio, la mayoria de mujeres que huyeron hacia Colomoncagua lo que mejor, cuando no únicamenle, sabian hacer eran los oficios domésticos: "echar tortillas, la alimentación, lo más básico: cocer arroz o Irijoles..." (Repatriada de Ciudad Segundo Montes). Su lugar de trabajo era la casa: "nadie salia. Como también los mismos padres nos IImltaban salir fuera. En la hembra no le permitían salir a buscar olro trabajito, to que tal vez ella consideraba que lo podía hacer; los padres no permitían" (ibid). Con la excusa de que "de las lelras no vas a vivir" tenian restringido el ya escaso acceso a la escuela: "hasta limitaban para que nosolros fueramos a la escuela... aunque tal vez a uno de nosolras nos gustaba ir a la escuela, pero los padres no los dejaban" (ibid). A las "hembras" se les exigla aprender a moler y hacer trabajo doméstico, pues es lo que les servirla para mantenerse dedicadas al cuido de los hijos y atención al compafiero de vida. Y esla siluación aparecía lan nalural que la mayoría de mujeres vivian "sin conciencia de sus verdaderas capacidades, ni de su situación de subyugada con respecto al hombre y dentro de la sociedad" (Comunidad Segundo Montes,1990:p.10). "Nalural" fue entonces que antes de los talleres en el refugio se haya inslalado una cocina colectiva para hacer tortillas. Alli se ocupaban bastantes mujeres. "Para nosotros era algo priorilario pues era la única forma que, con los escasos medios que tenlamos, las tortillas llegaran a loda la comunidad" (Refugiados en Colomoncagua, No.3) Poco a poco se dieron cuenta de que el oficio doméstico no basiaba' "donde alli ya el oficio doméstico para nosoIros considerabamos que ya no nos iba a ir dando tanlas garantias para poder sobrevivir. De alli ya se veia la necesidad de irnos organizando colectivamente, para ir entrentando a tos nuevos relos que en ese momento se nos presentaban" (Repatriada de Ciudad Segundo Montes). En todos los comités de trabajo: construcción, educación, alimentos, distribución de la producción, salud, relaciones, seclores y comunal, tuvo amplia participación la mujer. Por supuesto, "nosotros to hallamos dificil 
porque para cambiar la experiencia de la realidad que vivimos en el pais, a sólo lo doméstico, y allá en poco tiempo cambiar esa mentalidad fue difícil. Pero ya al final, la mayoría de mujeres fue viendo y enfrentando que si, la mujer tenia la capacidad de cambiar la forma de mentalidad y desempenar cualquier tarea que el hombre era el que tenla capacidad de hacerlo; la mujer la desempef́aba"(ibid).

Una siluación semejante vivieron las mujeres de Nueva Esperanza. "Vamos a pedir un proyecto donde nosolras podamos trabajar, porque no puede ser que sólo los hombres trabajen y nosotros como no andamos hombres.... también tenemos que ver cómo nos ganamos la vida. Así fue como fue surgiendo la integración al trabajo de nosolras" (Repatriada de Nueva Esperanza). Para impedir la separación del grupo que salió de San Roque, quedándose una parte en León y la otra cerca de Managua, un grupo de doce mujeres sin marido abrió la brecha. Un proyecto de "chanchas" primero, el sistema de riego y el trabajo en el campo después; "lirar el machele", mezclar abono, artesania, hacer escobas, coslura y panadería. Sin faltar educación y salud. Todas estas áreas fueron segmentos de la vida cotidiana para las mujëres en Nicaragua. Tanto que los hombres llegaron a admirarse y reconocer sus capacidades. No faltó, por supuesto, quién no estuviese de acuerdo. Hubo hombres que reclamaban: "¿cómo es que la mujer va a ir a trabajar? La mujer es de la casa; la mujer tiene que darse a la casa" (ibid). Para los hombres nicaragüenses de la cooperativa, la mujer no tenia fuluro. Mejor era que se casara. El casamiento sería la solución y el destino de las mujeres: "¡casate! nos decían los nicas, para que no vengás a trabajar; acompahate y ya vas a lerminar ese problema" (ibid).

Quizás la más grande experiencia-aprendizaje para las mujeres refugiadas en Ciudad Romero tue el simple hecho de vivir en comunidad. Y en ese contexlo, que sus Irabajos luviesen un carácter comunitario más que familiar. "Todo se hacia en común, para todos. Habia grupos de seforas que se turnaban, pero cocinaban para toda la comunidad. Unas se dedicaban al desayuno, otras al almuerzo y otras a la cena. Asi, por grupos pero para todos, en común" (Repatriada de Ciudad Romero). Mientras, los hombres se dedicaban a "botar montafia" y a construir las casas, las mujeres se organizaban en grupos para apoyarles, especialmenle en las tareas de alimentación. Cuando terminaron las casas comenzó el proyeclo del cacao y también allí se incorporaron: "iban semanas enteras las mujeres a cocinar, olras a llenar bolsas, a sembrar las semillas de cacao, y los hombres a botar montana y las mujeres a arrancar tierra". (ibid). Formaron comilés de amas de casa, luego grupos de sastreria, salud y un comilé de madres-maestras. 


\subsection{Un mundo nuevo de relaclones entre géneros se estába gestando.}

"Enlonces, nosotros hemos aprendido cosas que para nosolros los hombres, era bien dificil llegar a aceplarlas quizás, en que una mujer llegara a formar parte, en tomar una decisión que involucra, por ejemplo. a loda una sociedad...el derecho a la determinación, por ejemplo, de una mujer... quizás se vive en loda la repatriación. Nosotros hemos considerado que el juego (el papel) que la mujer hace en esa siluación es algo bien valioso" (Repalriado de Ciudad Romero). A pesar del carácter machista de los hombres del campo salvadoreno, la experiencia del relugio le habia hecho cambiar su percepción y valoración de la mujer, aceptaba que las mujeres lenían derecho a la realización no ya sólo como madres, esposas o companeras. Ellas son sujelas de historia también.

"Yo creo que en gran medida, los hombres que son miembros de nuestra comunidad, la experiencia de Colomoncagua les ha hecho reflexionar... ir borrando ese sistema que antes se vivia, que solo el hombre mandaba, que la mujer no tenia ninguna capacidad, ningún derecho... los hombres han logrado comprender que si, que la mujer tiene sus capacidades para poder trabajar también y que es importante la participación alli pues!" (Repatriada de Ciudad Segundo Montes). Unas relaciones más horizontales_enlre géneros se fueron gestando Relaciones de cooperación, de mayor respeto hacia la mujer.

También se fue valorando el trabajo y la vida comunitaria Como resullado de la relación con otra gente, la convivencia, "son experiencias que nos ayudaron mucho en la formación de esta comunidad, a vivir juntos y a cultivar el espiritu comunilario. Cosas que no las llevabamos Ahora, ya regresamos con un concepto diterente, con un modelo de vivir en comunidad que anles no lo teniamos. Son cosas que nos ayudaron mucho, son cosas que aprendimos fuera de El Salvador y que ahora acá las estamos impulsando" (Repatriado de Nueva Esperanza).

Aunque nos extendamos en citas de entrevistas, creemos que las palabras directas de hombres y mujeres repatriados, son parte del lestimonio de algunos cambios operados en la relación entre géneros y que podrian eslarse perdiendo en el contexto de la sociedad palriarcal que los expulsó y a la que han vuelto. He aqul otro ejemplo elocuente: "...el hombre ya deja que la mujer pueda participar en cualquier larea, para salir, que pueda ir a trabajar a otra parte y llegue a los dos o tres dias. No hay ningún problema; que ya el hombre comprende un poco más... y si nosotros no hubieramos salido (al exilio), quizás esluvieramos en lo mismo: que la mujer allí tenla que estar haciendo solo oficio, la cocina, criando hijos, haciéndole la comida al hombre y no pasaria de aquello. 
Decir que va a poder desarrollarse en algún proyeclo. Que pueda participar en algo más. La mujer, eso era en lo que antes se mantenia. Si nosotros no hubieramos salido de aqui, todavia vivieramos asi" (Repatriada de Ciudad Segundo Montes). ¿Y el haber regresado, pregunlamos nosotros, no estaría provocando que se pierda esa experiencia-aprendizaje muy beneficiosa para la comunidad, en general, y para las mujeres, en particular?

\subsection{La Repatrlacion: ¿un caballo de Troya?}

Si consideramos como proceso la organización de las comunidades de repalriados, ésta tuvo varias etapas, no necesariamente en el orden como las presentamos, ni siquiera en un orden lineal cronológico, sino "traslapadas" pero distinguibles:

- La ayuda mutua para la subsistencia y sobrevivencia, mientras no se les reconocia su eslatulo de relugiados.

- La defensa contra la amenaza militar y la violencia contra ellos.

- La resistencia para no ser trasladados y reubicados más lejos de su patria (al menos en el caso de los refugiados en Honduras).

- La demanda de mejores condiciones de vida y trabajo en el exilio.

- La organización y desarrollo de la producción, la educación, la salud, etc.

- El retorno a sus lugares de origen, la reconstrucción de sus vidas, economías y la aplicación de los conocimientos adquiridos en los campamentos.

Con sus matices, crearon comunidades con modelos de desarrollo socio-económico esperanzadores para "los más pobres de los pobres". Casi toda la población ha sido alfabetizada hasta el sexto grado. El nivel de salud ha bajado la tasa de morlalidad, han capacilado a niños, adullos, ancianos, en algún oficio y actividad. Su economía comprende la agricultura, el cultivo de horlalizas y frutas, granjas de animales comestibles tecnicamente llevadas, una producción fabril-arlesanal hasla la confección de muebles, vestido y calzado, recipientes metálicos, sombreros, hamacas, cerámica, juguetes, arte y artesanias (ECA,1989:p.783). Una muestra concrela de estos logros lo constituye el desarrollo alcanzado por la comunidad refugiada en Colomoncagua (ahora la comunidad Segundo Montes), en cuanto a personal capacitado en talleres y otras áreas hasta 1989, año en el cual se produce el retorno (Refugiados en Colomoncagua, No.3): 


\section{DESARROLLO DE LA COMUNIDAD}

- Personal capacitado en talleres y áreas.

\begin{tabular}{lcc}
\hline ARTESANAL & 1981 & 1989 \\
\hline Sastrería & 4 & 241 \\
Zapateria & 0 & 151 \\
Carpintería & 2 & 65 \\
Hojalatería & 0 & 63 \\
Alfarerla & 2 & 47 \\
Herrería & 0 & 15 \\
Jarcia & 25 & 126 \\
Fibras naturales & 0 & 111 \\
Artesania & 2 & 70 \\
Tejidos & 0 & 60 \\
Reparación y mantenimiento & 0 & 78 \\
AGROPECUARIO Y AGRICULTURA & & \\
& & \\
Granjas & 1 & 68 \\
Hortaliza y maíz & 0 & 318 \\
& & \\
AREA DE SERVICIOS & & \\
Personal de cocinas colectivas & & 516 \\
Personal de agua potable & 0 & 22 \\
Salud & 0 & 358 \\
Educación & 0 & 807 \\
Personal de distribución & 0 & 81 \\
Construcción & 0 & \\
\hline TOTAL...... & 0 & \\
\hline
\end{tabular}

"Nuestra comunidad ha aprendido cómo dar trabajo para todos, cómo dar educación para todos, cómo dar salud para todos... nuestro deseo es regresar en comunidad... queremos conservar el modelo de organización que actualmente tenemos..." (Relugiados en Colomoncagua, No.3).

Habia que relomar pues al pals y convertirse en testimonio, frente al resto de la sociedad, de lo que son capaces de realizar los pobres, 
dadas unas condiciones básicas: organización comunitaria, capacilaclón y ayuda externa.

Asi, desde 1987 hasla 1991, se llevaron a cabo una serie de repatriaciones colectivas que intentaron dar su aporle, desde dentro, a la viabilidad histórica de este país. ¿Y por qué repatriaciones colectivas? Entre otras razones, por las muchas viudas, huérlanos y ancianos que necesitarian ayuda de la comunidad, como garantla de su seguridad y de la alención de los organismos internacionales de ayuda y protección. Además, ya habian suficienles datos de que los repatriados de forma individual, pocos regresaban a sus lugares de origen, algunos fueron capturados, acusados de delitos políticos o se convirtieron en otros desplazados más.

Indudablemente, todos estos procesos de repatriación fueron obstaculizados por el Gobierno salvadorefio, los gobiernos de Honduras, Nicaragua y Panamá. Se obslaculizaban las fechas. los lugares de asentamiento y la forma colecliva de la repalriación. En lodos los casos, se traló de una lucha de meses e incluyó acciones como marchas, huelgas de hambre y toma de embajadas. En todas ellas, como ya se había hecho coslumbre, hubo una masiva participación de mujeres y nifos, además de los pocos hombres de las comunidades. "Cuando nos sacaron a bombazos, no nos sacaron ordenados" (Relugiado en Mesa Grande). Esta frase revela lo tenso del proceso de repalriación, pero también muestra la decisión inquebrantable del relorno. Es cierto, to menos que se podia decir y esperar de los repalriados era "que no apoyan, ni simpatizan, ni creen en las promesas ni en la buena voluntad del Gobierno y del ejército. Pero eso no los convierte en ninguna manera en guerrilleros, ni en "subversivos", ya que se mantienen como simples civiles... y que, como cualquier otro ciudadano, lienen derecho a tener sus propios valores sociales y opciones políticas" (ECA,1989:p.782).

\section{De refugladas a repatrladas.}

\subsection{De lo artiflcial al vlejo mundo (para hacerlo nuevo).}

"Porque hay que entender una cosa, nosotros tenemos que tomar en cuenta en que va a llegar un día en que no vamos a ser asistidos, porque ahorita todavía dependemos de eso, de que somos asistidos" (Repalriada de Ciudad Segundo Montes). Esta Irase expresa la conciencia de to artificial del modelo y por tanlo de la necesidad de inlroducir cambios que lo adecuaran a la realidad en los asentamientos. Asi se les impuso la gran larea de pasar de ser unas comunidades asistidas a unas comunidades en desarrollo, articuladas al resto de la nación. Ellos sabían que el 
cambio no iba a ser fácil. Si algo se podia notar rapidamente en la dirigencia de cada repatriación era la claridad en torno a esle problema. La planiticación se convirtió en una tarea fundamenlal. Lo pragmático, en tanto lo práctico y posible ya, se convirtió en otro criterio esencial en la gestión de estas comunidades. La experiencia-aprendizaje del exilio se convirtió en el eje de los modelos de desarrollo. La participación femenina no solo seguirá siendo importante sino necesaria si se quiere mantener y reproducir los logros en aquellas áreas que afectaban anles a las mujeres en tanto mujeres. De campesinas anallabetas pasaron a ser refugiadas en capacilación y luego. a repatriadas capacitadas en muchas áreas. Su visión del mundo y de la realidad social se ha visto ampliticada. Las relaciones con los hombres ya no son, hasla ahora, como antes del exilio. Sus perspectivas de desarrollo son mayores que las de otras mujeres campesinas del resto del pais. Claro que ésto sólo dentro de las repalriaciones o vinculadas a ellas. Las modificaciones en la inslitucionalidad-objetividad de la vida colidiana, logradas en el refugio-exilio, ahora deben consolidarse e impulsarse en las zonas vecinas para hacerse una estructura de plausibilidad que acompane a la modificación subjetiva de la realidad social internalizada antes del exilio. Si en muchos aspectos se había logrado la des-reilicación de la realidad social, ahora debe trabajarse por extender esa des-reiticación, es decir, por ayudar a develar el carácter humano/varón, y no de la naluraleza ni de orden divino, de muchas normas y formas de conducla-externalización social.

\subsection{Las primeras necesidades y obstáculos.}

Indudablemente que una de las primeras necesidades al retorno de las comunidades de repatriados tenía que ver con la reestructuración. $Y$ ésta se notó en la reorganización. En la aclualidad, enfrentan varios relos para lograr consolidarse y conlormar un modelo de desarrollo socio-económico alternativo para los pobres: la legalización de lodas sus acciones; el paso de la etapa de asislencia a la de un desarrollo sostenido en donde la producción agrícola o la producción semi-industrial resul: lan delerminantes; deben ampliar sus talleres para buscar un excedenle para la venta; formar un sistema educativo acorde al modelo propuesto; una continua capacitación vocacional, tanto en producción como en áreas de administración, comercialización y planificación; el desarrollo de la atención primaria en salud, tanto preventiva como de medicina especializada; desarrollar cooperalivas de ahorro y crédilo, proyectos de infraestructura, etc.

Uno de los mayores obsláculos, si no el determinante, que enfrentan los modelos de desarrollo de los repalriados tiene que ver con su inserción al sistema capitalista dependiente y subdesarrollado del pais. 
Deben competir bajo sus reglas de juego. Según sea el eje de acumulación asi son sus mayores o menores limilantes. Para los modelos cuyo eje es la agricultura, les resulla más tácil su incorporación al mercado. aunque quedan a despensas de condiciones climálicas que pueden llegar a ser determinantes. En todo caso, de su misma producción se proveen para la alimentación y para el comercio. No así, cuando el modelo descansa en un eje semi-industrial. En este caso, se hace necesaria la producción de excedentes y comercializarlos para generar ingresos para la alimentación cuando ésta no está garantizada por factores geográficos y para seguir produciendo.

Por la composición de la población de estas comunidades, la mujer está siendo mayormente afectada. Muchas mujeres no trabajan, por ahora, en los oficios aprendidos en el refugio y están volviendo. a los Irabajos domésticos. Los embarazos se constituyen, en este contexto, en un agravante de la siluación pues no están en las mejores condiciones para solventar esle problema, que en cierto sentido se convierte en obstáculo para el despegue del modelo de desarrollo de la comunidad. Más en general, el aspecto salud comunitaria representa una prioridad para que no se convierta, en ninguna de las repatriaciones, en un elemento que obligue a desviar fondos necesarios ya en los proyectos productivos. Garantizar la reproducción social será básico para el éxito en la produccion, pero ésta a su vez, es condición SINE QUA NON para la reproducción social del modelo. La ayuda financiera de agencias y la solidaridad internacional, han de permitir que no se genere un "círculo vicioso" entre reproducción y producción social. La eficiencia es responsabilidad de las comunidades para poder enfrenlar al sistema social y económico en que ahora eslán inmersos.

\subsection{Las grandes preguntas.}

El componente poblacional de las comunidades de repalriados continua siendo el mismo de antes del exilio. Pero sus logros hablan de una Iranslormación, de un cambio fundamenlal en ese tipo de población. Ya S.Montes lo decía de los refugiados en Colomoncagua: se han Iransformado en una población allabetizada en más del $85 \%$, organizados solidariamenle, que ulilizan métodos y lécnicas de cultivo nuevas, que dirigen granjas de animales con técnicas alimenlicias y sanilarias adecuadas, que manejan complicadas máquinas eléctricas y mecánicas, que planifican y contabilizan la producción, distribución e inventarios, población que lorma sus propios educadores y sanitarios, sus dirigentes y lodo recurso humano necesario para el desarrollo de su modelo, eic. (Montes, 1989:p.44). 
Poco a poco, las tareas y áreas de trabajo se han ido ampliando, desde las asumidas para mera subsistencia en los campamentos, hasla las actuales en los asentamientos. En todo esle proceso ha sido decisiva la participación de la mujer, como sujela de desarrollo y como mujer; por la NECESIDAD se vio torzada a asumir roles no tradicionales, a externalizarse de manera no tradicional, a Ingresar en la esfera de la producción social. Por condiciones coyunturales, irrepetibles, como la falta de hombres con capacidad productiva y su capacitación por parte de quienes les apoyaron en los refugios, la división sexual del trabajo se ví́ moditicada. Por el tipo de organización comunilaria y "artificial" en los campamentos, la distinción y valoración entre trabajo doméslico y trabajo social-público también ha suirido modificaciones favorables a la mujer. Queda la pregunla ¿si no seria más bien una exlensión de las tareas domésticas tradicionalmente femeninas? Podemos afirmar que existe una doble y hasla triple jornada de Irabajo para las mujeres repalriadas, y por tanto, ¿están en desventaja respecto de los hombres? De cara al futuro, un problema latente en los nuevos proyeclos de desarrollo es que se favorezca la vieja distribución de roles según sexo, a medida que participen mayor numero de hombres. La experiencia en olros paises ha ido demostrando que si los proyeclos de desarrollo no tienen incorporada una visión de género, pueden favorecer a la comunidad pero atectar negalivamente a las mujeres. De aqui que se puede alirmar que no se da aulomáticamente una mejoría en la situación de la mujer de una mejoria en la comunidad. Pero tampoco eslá demostrado lo contrario: que una mejoría en ta condición de la mujer respecto del hombre conlleve necesariamente una mejoría socio-económica en el grupo social. Pero sin mejora en la condición y siluación de la mujer, en lanlo mujer, no hay auténtico desarrollo social.

El proceso de las comunidades de repatriados es un caso "sui generis". La igualdad de oporlunidades y la horizontalidad en las relaciones entre géneros no ha sido produclo de una lucha feminisla. Es insoslayabTe lambién que se trata de unas condiciones muy distinlas a las del resto de mujeres campesinas del pals. El problema para las repatriadas parece planlearse de cara al futuro próximo, a medida que sea más estable y normal la existencia y desarrollo de esas comunidades y la presencia masculina se vaya incremenlando; cuando los problemas en lorno a la reproducción social y la sexualidad cobren relevancia mayor que los de la subsistencia colectiva

\section{Concluslones de la Invesilgación.}

La investigación desarrollada en las comunidades Ciudad Segundo 
Montes, Nueva Esperanza y Ciudad Romero nos sefiala que a partir de la experiencia-aprendizaje en el exilio, las mujeres de estas comunidades de repatriados ejecutan una serie de trabajos que tradicionalmente son asignados, en la sociedad palriarcal, a los hombres. En las tres comunidades se ha constalado el ingreso de la mujer a la esfera socialpública. Desde luego hay que hacer las malizaciones respeclivas, tanlo en la forma, la cantidad y el área de trabajo a que han ingresado. Pero esto no significa que los hombres hayan ingresado a la eslera doméslica como algo propio también para ellos. Queda claro lambién que el ingreso femenino al trabajo social-público ha signilicado para ellas una extensión en su "jornada de trabajo" a una "doble" y, en algunos casos, "triple" jornada de trabajo. Por olra parte, si atendemos a los dislintos roles que ejecutan en la eslera social, llegamos a la conclusión de que en su mayoría se trata de trabajos que pueden considerarse como extensión del trabajo doméstico: educación, salud, evangelización, bordado, cosiura, cocina, panadería, guarderia, alimentación, etc. En estas áreas, Ta mayor parte del personal es femenino, por lo que podriamos afirmar que si bien las mujeres repatriadas han ingresado a la esfera del trabajo social, to han hecho por "la puerla femenina", es decir, por trabajos mayoritariamente femeninos en el mundo social y en estrecha relación o continuación del trabajo doméstico.

Si consideramos el "mundo político" como "mundo tradicionalmenle de hombres", es aqui donde está la inserción de mayor significado y trascendencia para las mujeres. Antes del exilio eslaban definitivamenle "condenadas" al hogar como "puerto y cárcel". Ahora, con sus matices por supuesto, pero de manera irreversible, han ingresado al mundo donde se decide el fuluro del gnupo, a la eslera de las decisiones, a las directivas de la comunidad, a la dirección de los colectivos de producción y, por lo tanto, con capacidad de decidir ya no solo sobre su casa sino sobre el deslino de su grupo social en iguales condiciones que los hombres.

En general, exislen en todas las comunidades proyectos para tavorecer la incorporación de la mujer al trabajo comunitario. Asi lenemos: las guarderlas, los cultivos de hortalizas, de panaderia, de coslura, elc. Estos proyectos buscan además lograr excedentes económicos a través del comercio. Bien sea de la rama agricola o ya se trale de la rama semiindustrial importa la rentabilidad y no si son hombres o mujeres quienes los ejecuten. Hay otro tipo de proyectos, de infraestruclura, que incorporan a mujeres y hombres en su ejecución. Se Irala de proyectos cuyos destinalarios son los grupos familiares, como el caso de las viviendas, 0 bien de ubanizaciones, en cuyo caso es la comunidad entera la favorecida. A nivel de la base masculina (y probablemente de la base femenina) es probable que haya una percepción de que en lodo caso lo que se 
busca es el apoyo femenino al trabajo masculino y por tanto la lendencia sería reproducir la subordinación de la mujer al hombre aún en el Irabajo social. Juegan un papel decisivo las entidades, instituciones u organismos que les están apoyando ya sea con financiamiento o asesoria, para no perder de vista en sus proyeclos la igual diferencia social entre hombres y mujeres y no favorecer una desigual diferencia enlre géneros. No deben dejarse de lado programas específicos para mujeres, aquellos que van a las necesidades específicamente lemeninas.

La asignación de tareas en las comunidades de repatriados repite los criterios patriarcales-sexistas. Pero se han agregado nuevos criterios de setecctón en donde no importa el sexo: la capacitación recibida, ya sea en el exilio 0 aqui en los asentamientos; la responsabilidad y disciplina de la persona; el rendimiento, la edad y la pertenencia a un sector débil (ancianos, viudas, lisiados, elc).

Ahora bien, a pesar de que las mujeres repalriadas fueron objelo de un proceso de resocialización en el exilio, persisten en ellas estereotipos patriarcales de 10 que es ser mujer. En lodos los grupos estudiados inlervinieron agentes socializadores externos: la escuela formal, la iglesia, personas vinculadas a organizaciones socio-políticas, las mismas agencias $\theta$ instituciones que les asistieron. Todas ellas fueron sentando las bases para una nueva visión de la realidad. Por eso hablamos de procesos de re-socialización. Fundamentalmente se ha tratado de la internalización del mundo objetivado comunilariamenle. Por eso todos sefialan en su experiencia-aprendizaje la aceptación y vivencia de los valores comunitarios. Por supuesto que esta concepción de la vida lavoreció el sentimienlo de hermandad y de igualdad en tanto lodos participaban de un mismo destino. Ahora bien, hacia dentro de los grupos hay hombres y mujeres con patrones cullurales acentuadamente machistas antes del exilio dado su origen nural. $Y$ en el mundo subjetivo de las mujeres ciertamente han habido cambios importantes. En lo referente a la división sexual del trabajo, ésta ha cedido terreno, tanto en cuanto a roles sexuales como a la división trabajo doméstico (para mujeres) y trabajo social (para hombres). Pero en lo relativo al ser femenino/masculino las modificaciones son menores. Prevalecen estereotipos relacionados con la fuerza fisica. Sin embargo hày que hacer matizaciones según cada comunidad y según características propias de cada mujer como son la edad, el eslado civil, el número de hijos y el nivel educativo.

En sintesis, si bien es cierto que las mujeres de las comunidades de repatriados tienen un rol preponderante en la vida de la comunidad, ello no signitica que se hayan superado las relaciones patriarcales entre géneros en estos grupos. La urgencia de las tareas de subsistencia 
colectiva y la ausencia de hombres con capacidad producliva eslán a la base del cambio operado en el status socioeconómico de la mujer repatriada. Como difícilmente se repetirán las condiciones por las cuales pasaron las comunidades de repatriados (desgarramiento violento del orden institucional instaurado, ausencia significativa de hombres en capacidad productiva, primacia de los problemas de subsistencia, hostilidad del medio, etc.), el trabajo de superación de las estrucluras sociales patriarcales deberá enfatizarse en los grupos de población joven, en tanlo que éslos están aún en proceso de inlernalización de la realidad social. Si la discontinuidad en los procesos de socialización no se puede provocar en los grupos adultos, en quienes la realidad social está muy alincada, contrario a lo sucedido entre los repatriados, debe provocarse discontinuidad entre adullos y jóvenes (incluyendo niños) en la transmisión de la ideologia patriarcal de una generación a otra.

\section{REFERENCIAS BIBLIOGRÁFICAS.}

CIUDAD ROMERO (1991). Historia de Ciudad Romero. Boletin Ciudad Romero. San Salvador: mimeo.

COMUNIDAD NUEVA ESPERANZA (1991). Historia de la Comunidad Nueva Esperanza. Usulután, El Salvador: mimeo 3pp.

COMUNIDAD SEGUNDO MONTES (1990). Repatriados No.3. Morazán, El Salvador: Ciudad Segundo Monles.

CONCERTACION NACIONAL DE INSTITUCIONES DE APOYO Y ORGANIZACION DE LA POBLACION REFUGIADA, RETORNADA Y DESPLAZADA DE EL SALVADOR (1991). Diagnóstico Nacional sobre las repatriaciones masivas de El Salvador (Mesa Grande, Colomoncagua y San Antonio). San Salvador: mimeo.

ECA (1987). La repatriación de Honduras. Estudios Centroamericanos No.468 (pp.169-172). San Salvador: Universidad Centroamericana "José Simeón Cañas".

ECA (1989). El retorno de los salvadoreños refugiados en Honduras. Estudios Centroamericanos No.492 (pp.777-790). San Salvador: Universidad Centroamericana "José Simeón Cañas".

MONTES, SEGUNDO (1985). El Salvador 1985. Desplazados y Refugiados. San Salvador: Instituto de Investigaciones, Universidad Centroamericana "José Simeón Cañas".

MONTES, SEGUNDO (1988). Levanlamientos campesinos en El Salvador. Realidad económica y Social No. 1 (pp.79-100). San Salvador: Universidad Centroamericana "José Simeón Cañas".

MONTES, SEGUNDO (1989). Refugiados y Repatriados. El Salvador y Honduras. San Salvador: Departamento de Sociologia y Ciencias Pollticas-Instituto de Derechos Humanos-Universidad Centroamericana "José Simeón Cañas".

REFUGIADOS EN COLOMONCAGUA. Boletines informativos. Colomoncagua, Honduras: mimeo. 